\title{
SPATIAL ANALYSIS OF PROSTATE CANCER INCIDENCE IN IRAQ DURING 2000- 2015
}

\author{
Muzahem Mohammed AL-Hashimi \\ Department of Statistics and Informatics, College of Computer science \& Mathematics, University of Mosul, Mosul, Iraq.
}

Corresponding author: Muzahem Mohammed AL-Hashimi

Email: muzahim_alhashime@uomosul.edu.iq

\begin{abstract}
Prostate cancer incidence rates have evidenced a substantial increase in Iraq over the past sixteen years. Geographic variation of prostate cancer in Iraq has not been explored. We examine the geographic incidence patterns of prostate cancer in Iraq using the global index of spatial autocorrelation, Getis-Ord Gi* and Anselin Local Moran's I to detect hotspots, coldspots, and spatial outliers of prostate cancer rates. We calculated the age-adjusted incidence rates (AAIRs) according to district level for three periods (2000-2004, 2005-2009, and 2010-2015). Disease maps were produced to explore whether prostate cancer incidence clusters by district, and where hotspots and coldspots occur. Results highlight several districts of Iraq where the burden of prostate cancer incidence is especially high. In 20052009, the spatial autocorrelation analysis revealed a prostate cancer incidence hotspot in Al-Rissafa, Al-Manathera, Al-Kufa, Al-Hilla, Al-Hindiya, and Kerbela district. In 2010-2015, hotspots were seen in Al-Mussyab, Al-Hilla, Al-Hindiya, Al-Rissafa, Al-Adhamiya, Al-Sadir, and Daquq district. Examining spatial pattern of prostate cancer AAIRs is critical to government efforts to focus on those regions, and to understanding and targeting prostate cancer.
\end{abstract}

Keywords: Spatial variation; Coldspots; Hotspots; Spatial outliers.

\section{INTRODUCTION}

Globally, prostate cancer ranked second (after lung cancer) in cancer incidence and fifth in cancer deaths for males in 2018, with an estimate of 1,276,106 new cases and 358,989 deaths occurred $^{1}$. Prostate cancer caused 6,300,000 disability-adjusted life years globally in 2015, with $82 \%$ coming from years of life lost due to premature mortality (YLLs) and $18 \%$ from years of healthy life lost due to disability (YLDs)2. Prostate cancer incidence and mortality are strongly related to the age with the highest incidence being seen in older men ( $>65$ years of age $)^{3}$. The age-standardized incidence rates and age-standardized death rates for prostate cancer in 2018 were the lowest in south central Asia $(5.0 / 100,000)$ and Northern Africa $(13.2 / 100,000)$. Conversely, they were the highest in Northern Europe $(85.7 / 100,000)$, Australia and New Zealand (85.4/100,000), followed by Western Europe $(75.8 / 100,000)^{3}$. Trends of prostate cancer incidence towards an increase worldwide with $1,017,712$ new cases up to 2040 is estimated. The highest incidence will be registered in Africa, followed by Latin America, the Caribbean and Asia. Conversely, the lowest incidence will be registered in Europe ${ }^{3}$. Most researchers agree that no single risk factor is responsible for most cases of prostate cancer. This increase in the incidence rates appears to be related to an increased life expectancy, physical inactivity and dietary factors ${ }^{3,4}$.

In Iraq, prostate cancer ranked as the most frequent type of cancer among male. The incidence rates of prostate cancer have risen substantially over the study period ${ }^{5}$. Although many studies have investigated the epidemiology of prostate cancer in specific provinces in Iraq $^{6-8}$, but the spatial patterns at the province or district-level have not been examined. Describing how districts with high or low prostate cancer AAIRs cluster geographically may aid government efforts to reduce prostate cancer rates in specific areas of Iraq. This study aimed to examine whether Prostate cancer AAIRs show evidence of clustering using the information obtained from the Iraqi Cancer Registry, to distinguish where hotspots and cold spots appear (groups of districts with extremely high or low AAIRs of prostate cancer), and to distinguish spatial outliers (districts with high or low AAIRs of prostate cancer surrounded by districts with dissimilar values), during the study periods.

Iraq is a developing country located in western Asia, bordered by Turkey in the North, Iran in the East, Kuwait in the southeast, Saudi Arabia in the South, Jordan in the southwest, and Syria in the west. It has a total area of $437,072 \mathrm{~km}^{2}$. Administratively, the country is divided into 18 provinces (three of which are designated officially as a Kurdish autonomous region) with 113 districts. The estimated population of Iraq as on mid-year 2020, according to UN data, is $40,222,493$. Figure 1 shows the location of Iraq.

\section{METHODS}

Data

This study covers all provinces with the exception of three provinces in Kurdish region (Erbil, Duhok 
and Al-Sulaymaniyah, for which the data is incomplete) with 83 districts in the country during 2000-2015. Data on the number of prostate cancer incidence cases for the years 2000-2015 were obtained from Iraqi Cancer Registry (ICR). The ICR was established in 1974 through close cooperation of the Ministry of Health and Iraqi Cancer Society. It began collecting annual data in 1975 from medical record departments of all hospitals (public and private), radiotherapy and pathology departments, and public and private labs in all provinces of Iraq. For each reportable case, information including registry number, name, gender, age, nationality, address, phone number, occupation, cancer site, diagnose date, ICD-10 code, basis for diagnosis, grade, treatment, and the hospital name and location were registered. The completed records are entered into "Alphabetical Index" to prevent duplication ${ }^{5}$. All cancers of the prostate cancer (ICD-10 codes C61) were included in the analysis. The annual estimates of the district resident populations by age group during the period 20002015 were obtained from the Central Organization for Statistics in Ministry of Planning. To enhance statistical stability for examine spatial pattern of prostate cancer, the data were divided into three time periods (2000-2004, 2005-2009, and 20102015). The AAIRs were calculated according to district level for each time period (2000-2004, 2005- 2009, and 2010-2015) using the world standard population. All maps were created using ArcGIS 10.6 (ESRI, Redlands, CA, USA). Statistical significance was assumed at $p<0.05$. We used six age groups (i.e. $\leq 39,40-49,50-59,60-69,70-79$, and $\geq 80$ ). Examining spatial pattern of prostate cancer AAIRs is critical to government efforts understanding and targeting prostate cancer.

\section{Statistical analysis}

\section{Global spatial autocorrelation - Moran's I}

Global Moran's I of spatial autocorrelation was used to evaluate the similarity across districts with respect to prostate cancer. In other words, do districts with similar prostate cancer AAIRs tend to cluster spatially or are prostate cancer AAIRs randomly distributed across districts in Iraq? The Global Moran's I statistic is given as follows':

Where:

$$
I=\frac{n \sum_{i} \sum_{j} W_{i, j}\left(X_{i}-\bar{X}\right)\left(X_{j}-\bar{X}\right)}{\sum_{i} \sum_{j} W_{i, j}\left(X_{i}-\bar{X}\right)^{2}}
$$

$X_{i}=$ the AAIRs of prostate cancer for the ith district;

$X_{j}=$ the AAIRs of prostate cancer for the $j$ th district;

$\bar{X}=$ the mean of AAIRs of prostate cancer for all of the districts in the study area;

$W_{i, j}=$ the spatial weight between pair of districts $i$ and $j$; and

$n=$ the total number of districts.

An $I$ that is significantly greater than 1 indicates a clustered pattern (i.e., similar prostate cancer AAIRs located close together), $I=0$ indicates a random pattern, and $I$ that is significantly less than 1 indicates a dispersed pattern (i.e., nearby districts have very different prostate cancer AAIRs).

\section{Getis-Ord $\mathrm{Gi}^{*}$ statistic}

Getis-Ord $G_{i}^{*}$ statistic was used to distinguish specific clusters of high/low prostate cancer AAIRs. The Getis-Ord $G_{i}^{*}$ statistic is given as follows ${ }^{10}$ :

Where:

$$
G_{i}^{*}=\frac{\sum_{j=1}^{n} W_{i, j} X_{j}-\bar{X} \sum_{j=1}^{n} W_{i, j}}{S \sqrt{\frac{n \sum_{j=1}^{n} W_{i, j}^{2}-\sum_{j=1}^{n} W_{i, j}}{n-1}}}
$$

$X_{i}=$ the AAIRs of prostate cancer cancers for the ith district;

$\bar{X}=$ the mean of AAIRs of prostate cancer for all of the districts in the study area;

$W_{i, j}=$ the spatial weight between pair of districts $i$ and $j$;

$n=$ the total number of districts; and

$S=$ the standard deviation of the AAIRs of prostate cancer in the study area.

The Getis-Ord Gi* statistic creates a z-score and $p$-value for each district, where $z>1.96$ and $(p<$ 0.05 ) indicate the more intense the clustering of high values "hotspot" and $z<-1.96(p<0.05)$ delineate the more intense the clustering of low values "coldspot". A z score near zero delineate no apparent spatial clustering.

\section{The Anselin local Moran's I}

The Anselin local Moran's I delineates statistically significant spatial clusters of districts with high or low AAIRs as well as spatial outliers. Clusters of districts with high AAIRs and surrounded by high AAIRs (high-high or $\mathrm{HH}$ ) were considered "hotspots", whereas clusters of districts with low AAIRs and surrounded by low AAIRs (low-low or LL) were considered "coldspots." In addition, the local Moran's I delineates districts with higher AAIRs that are surrounded by districts with lower AAIRs (high-low or $\mathrm{HL}$ ), as well as districts with lower AAIRs that are surrounded by districts with higher AAIRs (low-high or LH). The Anselin local Moran's I statistic is given as follows ${ }^{11}$ :

$$
I_{i}=\frac{\left(X_{i}-\bar{X}\right) \sum_{j} W_{i, j}\left(X_{j}-\bar{X}\right)}{S^{2}}
$$

Where:

$X_{i}=$ the AAIRs of prostate cancer for the ith district;

$\bar{X}=$ the mean of AAIRs of prostate cancer for all of the districts in the study area;

$X_{j}=$ the AAIRs of prostate cancer for the $j$ th district;

$W_{i, j}=$ the spatial weight between pair of districts $i$ and $j$;

$n=$ the total number of districts; and

$S=$ the standard deviation of the AAIRs of prostate cancer in the study area. 


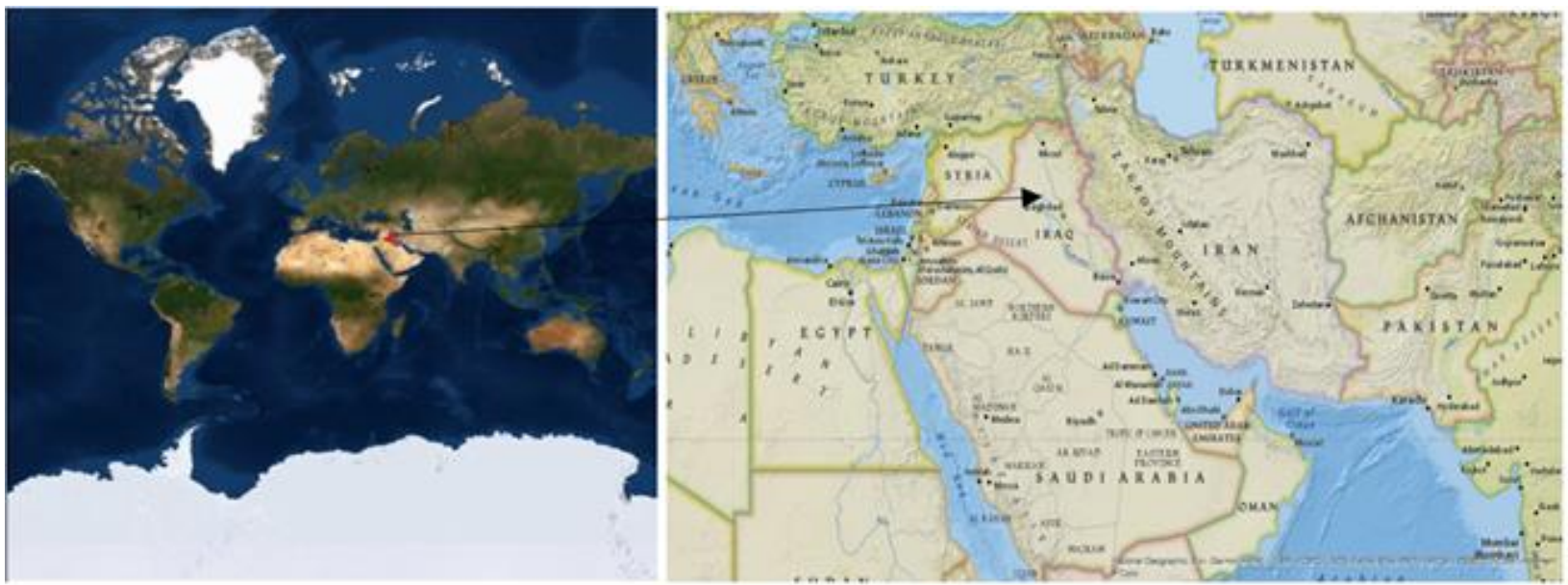

Figure 1. The location of Iraq

\section{RESULTS}

\section{Descriptive statistics}

Between 2000 and 2015, a total of 4770 prostate cancer cases were reported in Iraq (except Kurdish region), which accounted for approximately $4.08 \%$ of the cancer cases among men, and prostate cancer ranked as the most common type of men cancer. The Age-specific incidence rates (ASIRs) rise steadily from age 50 59 , the highest rates are in the 70 to 79 age group $(A S I R s=87.60) \quad($ Figure 2a). The age-adjusted prostate cancer incidence rate in Iraq substantially increased from 3.60 per 100,000 in 2000-2004 to 5.01 per 100,000 in 2005-2009, and to 9.10 (Figure 2b). The five districts with the highest AAIRs of prostate cancer for each period were shown in Table 1 and Figures 3A,3B, and 3C.

\section{Global spatial autocorrelation}

The global Moran's I statistics of the AAIRs of prostate cancer were calculated for each of the three time periods. The Moran's $I$ Index for the years 2000-2004 was $0.067(Z=1.419, P<0.156)$, suggesting that the spatial distribution of prostate cancer had a random distribution pattern. The results were similar across the two time periods (2005-2009) and (2010-2015), with positive spatial autocorrelation estimates (Moran's $I$ index $=0.116$ $(z=3.246, p<0.001)$ for the period 2005-2009, and Moran's $I$ index $=0.102(z=2.801, p<0.005)$ for the period 2010-2015) indicating that the spatial distribution of prostate cancer in Iraq had spatial autocorrelation in each of those two periods. In other words, across Iraq, districts with similar AAIRs rates tend to cluster together in each of the two periods 2005-2009 and 2010-2015.

\section{Hotspot and coldspot analysis - Getis-Ord Gi ${ }^{*}$}

Significant spatial clusters of districts with high (hotspots) and low (coldspots) AAIRs, as evaluated by the Getis-Ord $\mathrm{Gi}^{*}$ statistic for each of the two time periods (2005-2009) and (2010-2015) can be seen in Table 2 and Figures 4, A and B. In (20052009), 8 districts were categorized as part of a hotspot, and 1 district was categorized as part of a coldspot (Table 2 and Figure 4A). In (2010-2015), the number of districts identified as part of a hotspot increased to 9 and the number of districts that categorized as part of a coldspot increased to 5 (Table 2 and Figure 4B).

Table 1. Districts with the highest AAIRs of prostate cancer during the periods, 2000-2004, 20052009, and 2010-2015

period

2000-2004

2005-2009

2010-2015

\section{districts}

Ain- Al-Tamur

Daquq

Al-Karkh

Rissafa

Al-Hawiga

Al-Najaf

Daquq

Al-Karkh

Al-Hilla

Rissafa

Al-Karkh

Al-Najaf

Tikrit

Al-Hilla

Kerbela
AAIRs per 100,000

11.50

10.70

8.60

7.90

7.80

16.30

11.40

11.30

9.70

8.60

18.20

15.80

15.20

14.50

14.20 
Table 2. Districts with the Hotspots and Coldspots of prostate cancer during the periods, 2005-2009, and 2010-2015

\begin{tabular}{|c|c|c|c|}
\hline Period & Category & Districts & Province \\
\hline \multirow[t]{8}{*}{$2005-2009$} & hotspots & Al-Rissafa & Baghdad \\
\hline & & Al-Najaf & Al-Najaf \\
\hline & & Al-Manathera & Al-Najaf \\
\hline & & Al-Kufa & Al-Najaf \\
\hline & & Kerbela & Kerbela \\
\hline & & Al-Hindiya & Kerbela \\
\hline & & Al-Hilla & Babil \\
\hline & & Kirkuk & Kirkuk \\
\hline \multirow[t]{9}{*}{$2010-2015$} & high-high & Al-Kadhmiyah & Baghdad \\
\hline & & Al-Sadir & Baghdad \\
\hline & & Al-Rissafa & Baghdad \\
\hline & & Al-Karkh & Baghdad \\
\hline & & Al-Mussyab & Babil \\
\hline & & Al-Hilla & Babil \\
\hline & & Al-Hindiya & Kerbela \\
\hline & & Daquq & Kirkuk \\
\hline & & Kirkuk & Kirkuk \\
\hline 2005-2009 & coldspots & Rawa & Al-Anbar \\
\hline \multirow[t]{5}{*}{$2010-2015$} & coldspots & Ana & Al-Anbar \\
\hline & & Rawa & Al-Anbar \\
\hline & & Al-Hatra & Ninewa \\
\hline & & Al-Baaj & Ninewa \\
\hline & & Sinjar & Ninewa \\
\hline
\end{tabular}

\section{Anselin Local Moran's I}

The local spatial autocorrelation analysis identified significant clusters of districts with either high or low AAIRs (e.g., HH or high-high and LL or low-low) and clusters where the nodal district and its neighbors differed significantly. In other words, across Iraq, where a nodal district has a high AAIR and adjacent districts low AAIRs, which is defined as a (high-low or $\mathrm{HL}$ ) cluster. Conversely, which is defined as a (low-high or LH) cluster.

Anselin Local Moran's I (cluster and outlier analysis) confirmed the significant hotspots (high- high) and coldspots (low-low) delaminated by the Getis Ord G * tool.

Table 3 and Figure 5, A and B showed the LISA analysis. In 2005-2009, the result showed the presence of a hotspot (high-high) of prostate cancer incidence in 6 districts. Coldspots (lowlow) were seen in 8 districts. Additionally, two districts were identified as spatial outliers (highlow) (Table 3 and Figure 5A). In 2010-2015, hotspots were seen in 7 districts. Coldspots were seen in 5 districts. Additionally, 5 districts were identified as spatial outliers (high-low). Conversely, there were 3 districts identified as the (low-high) type of spatial outlier (Table 3 and Figure 5B).
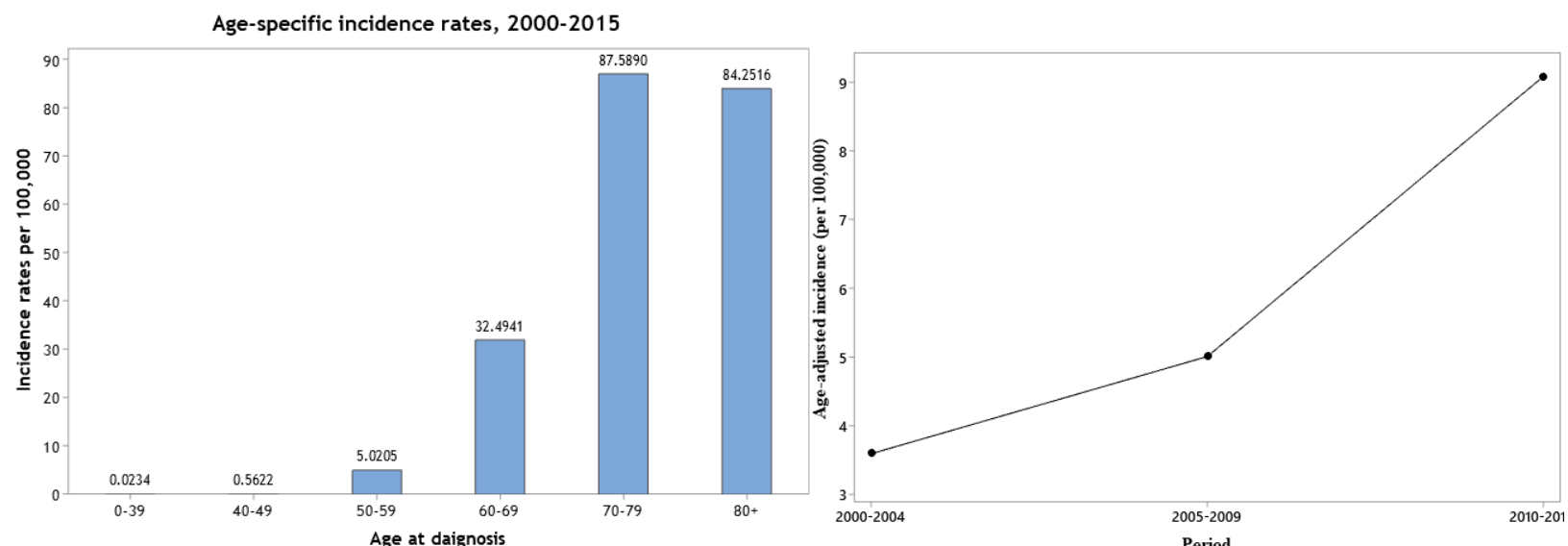

Figure 2. Age-specific incidence rates (ASIRs) for prostate cancer by age group (A) and incidence trends $(2000-2015)(B)$ 


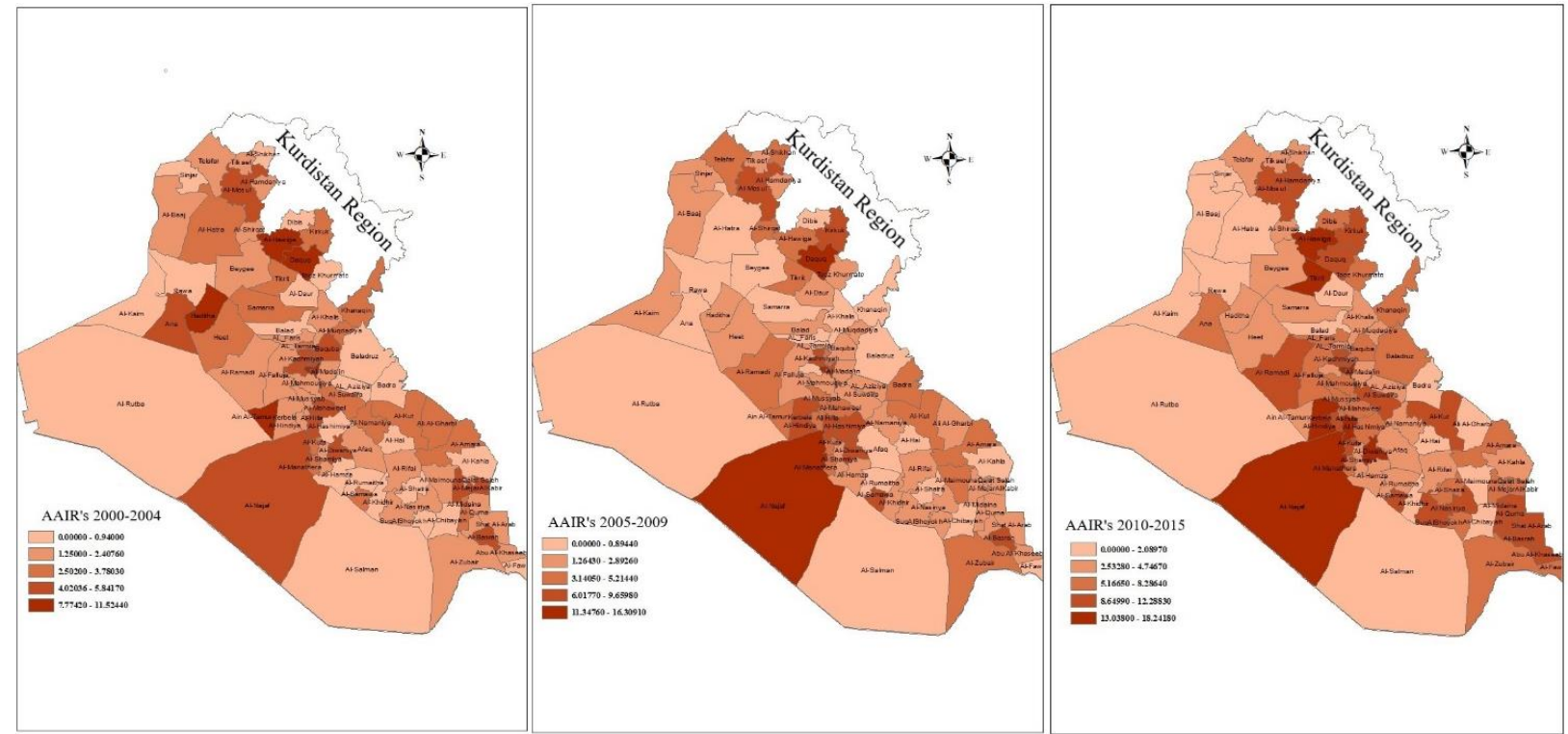

Figure 3. prostate cancer AAIRs (per 100,000) by districts. (A) the AAIRs during, 2000 to 2004. (B) the AAIRs during, 2005 to 2009. (C) the AAIRs during, 2010 to 2015.

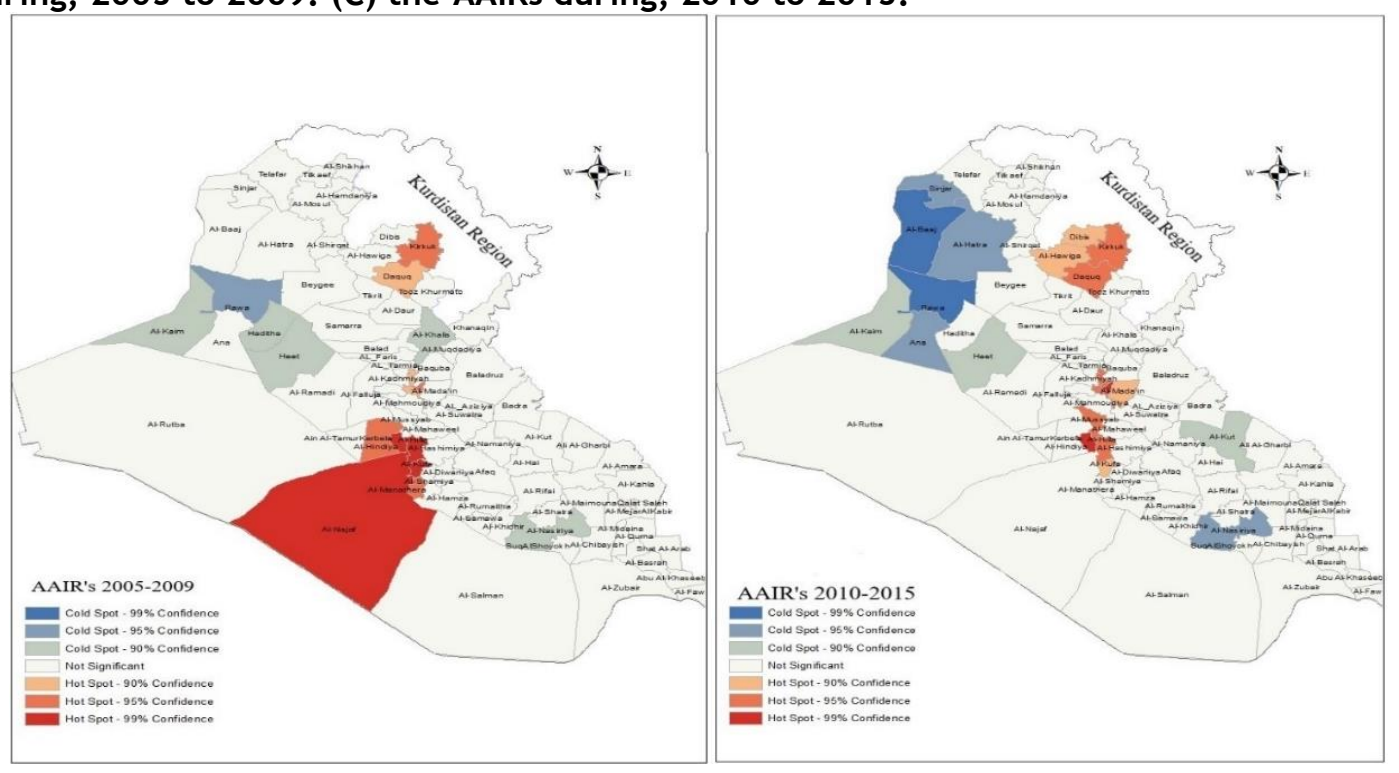

Figure 4. Hotspots and Coldspots of prostate cancer AAIRs. (A) for the period 2005 to 2009. (B) for the period 2010 to 2015.

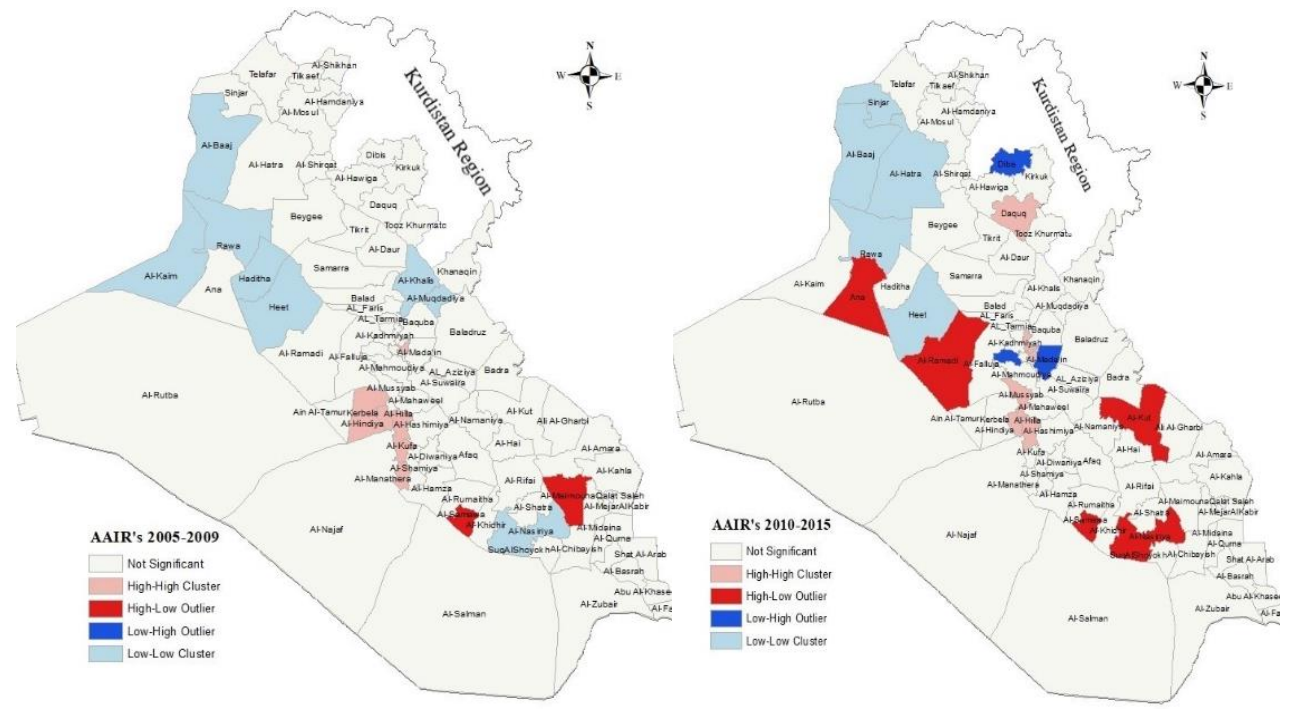

Figure 5. Clusters and spatial outliers of prostate cancer AAIRs. (A) for the period 2005 to 2009. (B) for the period 2010 to 2015. 
Table 3. Districts with the high-high, Low-low, high-low and low-high of prostate cancer during the periods, 2005-2009, and 2010-2015

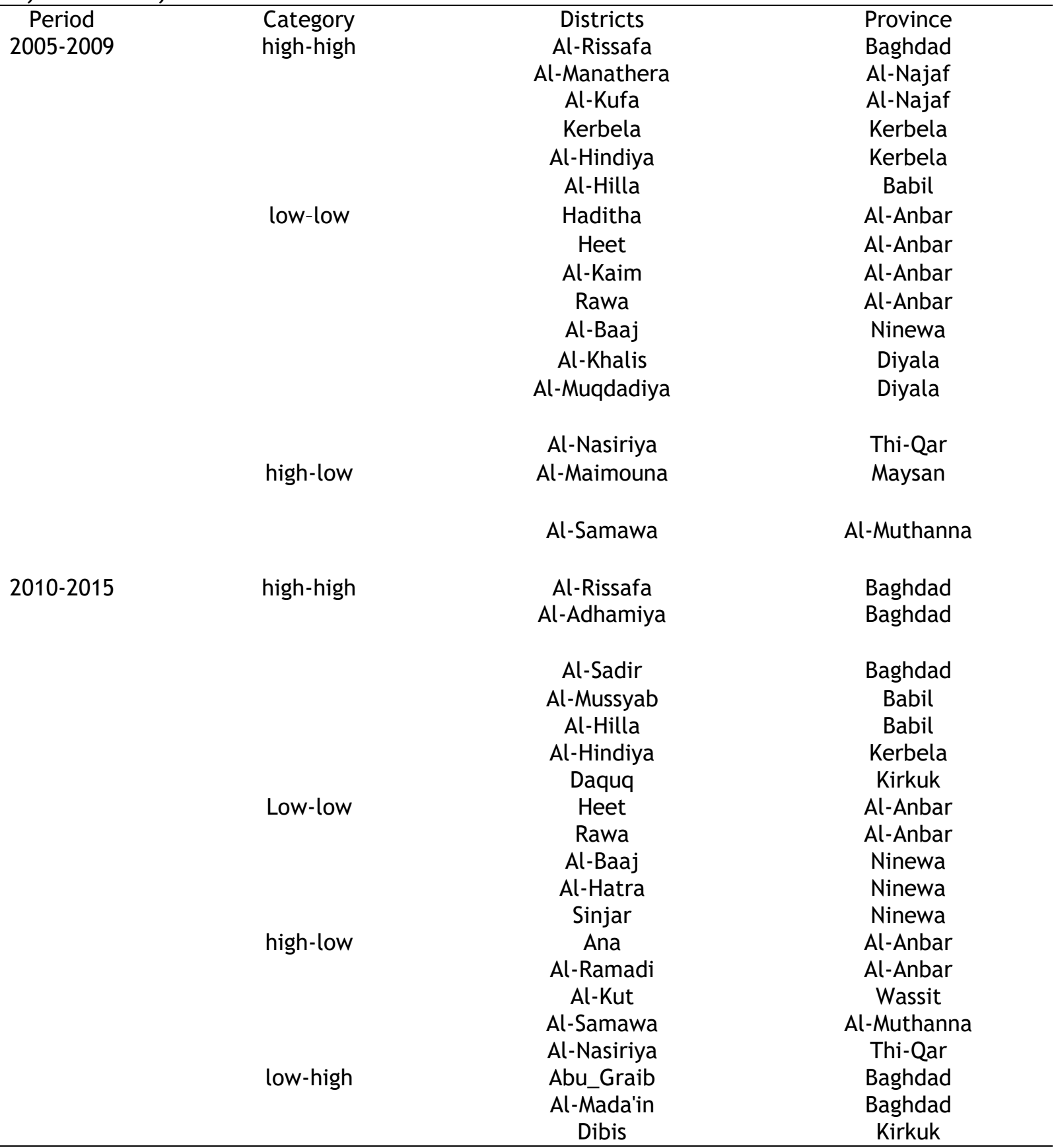

\section{DISCUSSION}

Globally, there is large variations in the burden of prostate cancers, it is the most commonly diagnosed cancer among men in over one-half (105 of 185) of the countries ${ }^{1}$ with higher prevalence in the developed countries ${ }^{3,12}$. The prostate cancer AAIR of 9.096 (2010-2015) which we found in this study, is lower than the average in developed countries such as Northern Europe $(85.7 / 100,000)$, Australia and New Zealand $(85.4 / 100,000)^{3,12}$, Turkey $(35 / 100,000)^{13}$ and most Arab countries such as Saudi Arabia $(9.5 / 100,000)$, Syria $(11.9 / 100,000)$ higher than that in Egypt $(7.8 / 100,000)^{14}$. Our results suggested higher age-specific incidence rates of prostate cancer among age group (70-79), with a lower age-specific incidence rates for patients aged $<50$ years, which is in line with most studies $^{13}, 15-20$, and consistent with the known characteristics of prostate cancer that is the most common among elderly men ${ }^{12,21-22 .}$

At present, the spatial patterns at the province or district-level have not been studied in Iraq. This article is the first to explore the geographic incidence patterns of the prostate cancer in Iraq using three spatial statistical techniques, Global index of spatial autocorrelation was applied to examine the similarity across districts with respect to prostate cancer AAIRs, Getis-Ord Gi ${ }^{*}$ and Anselin Local Moran's I. These techniques were used to assess clusters of districts with high or low prostate cancer AAIRs.

There is large geographic variation in AAIRs due to prostate cancer in Iraq. Results of global spatial 
autocorrelation analysis confirm that AAIRs exhibit spatial dependence in each of the two periods (2005-2009) and (2010-2015). In other words, across the entire Iraq, districts with high prostate cancer AAIRs tend to cluster together spatially. Conversely, districts with low prostate cancer AAIRs also tend to cluster together spatially. Using Getis Ord $\mathrm{Gi}^{*}$ tool we were able to delineate several hotspots and coldspots in Iraq that represent clusters of districts with significantly high or low prostate cancer AAIRs. In (2005-2009), the hotspots detected occurred in Al-Manathera, Al-Kufa, Al-Hilla, Al-Hindiya, Kerbela, Al-Najaf, Al-Rissafa, and Kirkuk district. In (2010-2015), the hotspots detected occurred in Al-Kadhmiyah, Al-Sadir, Al-Rissafa, Al-Karkh, AlMussyab, Al-Hilla, Al-Hindiya, Daquq, and Kirkuk district.

While the underlying reasons for the geographic variation in the frequency and distribution of prostate cancer are relatively little is known, they may be due to a variety of risk factors such as an aging, ethnicity, family history, obesity, Alcohol consumption, Cigarette smoking, Chronic inflammation and prostatitis, Environmental carcinogens, living in disadvantaged areas, and genetic factors increasing the risk of prostate cancer $3,12,23$. However, it is beyond the aim of this paper to know the reasons of geographical variation of prostate cancer incidence in Iraq. The causes of this spatial pattern of prostate cancer in Iraq are unknown, but they may be due to the aging, family history, obesity, Cigarette smoking, disadvantaged areas, Chronic inflammation and prostatitis, Environmental carcinogens. However, the reasons for the higher incidence rates in some districts merits further epidemiological studies related to the risk factors.

A recent study in Iraq showed an association of CYP1A1 rs1048943 polymorphism with prostate cancer in Iraqi men patients ${ }^{24}$. Another study conducted in capital of Baghdad by Khudur ${ }^{25}$ showed that majority (85\%) prostate cancer patients were living in disadvantaged areas, the aging ( $\geq 66)(40 \%)$, and most $(32 \%)$ of them had been smoking more than 20 years ${ }^{25}$.

\section{CONCLUSIONS}

At present, the geographic variation of prostate cancer across Iraq have not been explored in Iraq. This article is the first to explore the geographic variation of the prostate cancer in Iraq using spatial autocorrelation analyses. Moreover, it is the first to explore whether the incidence of the prostate cancer in Iraq tends to cluster together at the district level using Global index of spatial autocorrelation and Local indicators of spatial association (Getis-Ord $\mathrm{Gi}^{*}$ and Anselin Local Moran's I). Results suggest that there is a significant spatial autocorrelation among the prostate cancer AAIRs in Iraq for each of the periods (2005-2009) and (2010-2015). Districts with high and low incidence rates due to prostate cancer tend to cluster spatially. In 2005-2009, several hotspots were identified, Al-Rissafa, AlManathera, Al-Kufa, Al-Hilla, Al-Hindiya, and Kerbela district. Coldspots were seen in Haditha, Heet, Al-Kaim, Rawa, Al-Baaj, Al-Khalis, AlMuqdadiya, and Al-Nasiriya district. In 2010-2015, hotspots were identified in Al-Mussyab, Al-Hilla, Al-Hindiya, Al-Rissafa, Al-Adhamiya, Al-Sadir, and Daquq district. Coldspots were seen in Heet, Rawa, Al-Baaj, Al-Hatra, and Sinjar. Examining spatial pattern of prostate cancer AAIRs is critical to government efforts to focus on those regions, and to understanding and targeting prostate cancer.

\section{ACKNOWLEDGMENTS}

We would like to express our thanks to the staff of Iraqi Cancer Board-Ministry of Health for their effort for providing data access. We are grateful to university of Mosul, for supporting our work.

\section{CONFLICT OF INTEREST}

We declare that we have no conflicts of interest to disclose regarding this manuscript.

\section{FUNDING}

This manuscript received no specific grant from any funding agency in the public or commercial sectors.

\section{REFERENCES}

1. Bray F, Ferlay J, Soerjomataram I, Siegel RL, et al. Global cancer statistics 2018: GLOBOCAN estimates of incidence and mortality worldwide for 36 cancers in 185 countries. CA Cancer J Clin. 2018 Nov;68(6):394-

424.https://acsjournals.onlinelibrary.wiley.co $\mathrm{m} /$ doi/full/10.3322/caac.21492

2. Fitzmaurice C, Allen C, Barber RM, et al. Global, regional, and national cancer incidence, mortality, years of life lost, years lived with disability, and disabilityadjusted life-years for 32 cancer groups, 1990 to 2015: a systematic analysis for the global burden of disease study. JAMA oncology. $2017 \quad \mathrm{Apr} \quad$ 1;3(4):52448.https://jamanetwork.com/journals/jamao ncology/fullarticle/2588797

3. Rawla P. Epidemiology of prostate cancer. World J. Oncol. 2019 Apr;10(2):63.https://www.ncbi.nlm.nih.gov/ pmc/articles/PMC6497009/

4. Benke IN, Leitzmann MF, Behrens G, et al. Physical activity in relation to risk of 
prostate cancer: a systematic review and meta-analysis. Ann. Oncol. 2018 May $1 ; 29(5): 1154$ -

79.https://www.annalsofoncology.org/article /S0923-7534(19)34542-9/pdf

5. Annual Statistical Report 2015. Planning Directorate, Ministry of Health/ Environment, Republic of Iraq 2016: 4-5. https://moh.gov.iq/upload/upfile/ar/833.pdf

6. Hussain RA, Habib OS. Incidence of cancer in Basrah: results of a household survey. Asian Pac J Cancer Prev. 2015;16:163http://journal.waocp.org/article_30407_8d8c 29b5eb75f6ed408b82fa0a4893c6.pdf

7. Al-Janabi AA, Naseer ZH, Hamody TA. Epidemiological study of cancers in IraqKarbala from 2008 to 2015. Int J Med Res Health Sci. 2017;6(1):79 https://www.ijmrhs.com/medicalresearch/epidemiological-study-of-cancersin-iraqkarbala-from-2008-to-2015.pdf

8. Khoshnaw N, Mohammed HA, Abdullah DA. Patterns of cancer in Kurdistanresults of eight years cancer registration in Sulaymaniyah Province-Kurdistan-Iraq. Asian Pac J Cancer Prev. 2015;16(18):8525-31

http://journal.waocp.org/article_31772_6d67 93bd5678da4f2ce86876bf5834dc.pdf

9. Wong DW, Lee J. Statistical analysis of geographic information with ArcView GIS and ArcGIS. Hoboken, NJ: John Wiley \& Sons; 2005.

10. Ord JK, Getis A. Local spatial autocorrelation statistics: distributional issues and an application. Geogr. Anal. 1995 Oct;27(4):286-306. https://onlinelibrary.wiley.com/doi/pdf/10.1 111/j.1538-4632.1995.tb00912.x

11. Anselin L. Local indicators of spatial association-LISA. Geogr. Anal. 1995;27(2): 93-115. https://onlinelibrary.wiley.com/doi/pdf/10.1 111/j.1538-4632.1995.tb00338.x

12. Bray F, Lortet-Tieulent J, Ferlay J, et al. Prostate cancer incidence and mortality trends in 37 European countries: an overview. Eur. J. Cancer. 2010 Nov 1;46(17):3040-

52.DOI:https://doi.org/10.1016/j.ejca.2010.0 9.013

13. Zorlu F, Zorlu R, Divrik RT, et al. Prostate cancer incidence in Turkey: an epidemiological study. Asian Pac J Cancer Prev. 2014 Jan 1;15(21):9125- 30.http://journal.waocp.org/article_30071_c 7b0667d38c475dc724db6ebdff4db27.pdf

14. Al-Abdin OZ, Al-Beeshi IZ. Prostate cancer in the Arab population: an overview. Saudi Med J. 2018;39(5):453.https://www.ncbi.nlm.nih.g ov/pmc/articles/PMC6118189/pdf/SaudiMed J-39-453.pdf

15. Al-Tmemi MB. Epidemiological Study of Patients with Prostate Cancer in South of Iraq. University of Thi-Qar Journal of Science. 2014;4(3):72-6. https://www.iasj.net/iasj?func=fulltext\&ald= 92674

16. Ifere GO, Abebe F, Ananaba GA. Emergent trends in the reported incidence of prostate cancer in Nigeria. CLIN EPIDEMIOL. 2012;4:19.

https://www.ncbi.nlm.nih.gov/pmc/articles/P MC3266866/pdf/clep-4-019.pdf

17. Merrill RM, Morris MK. Prevalencecorrected prostate cancer incidence rates and trends. Am. J. Epidemiol. 2002;155(2):148-52.

https://academic.oup.com/aje/article/155/2/ 148/108029

18. Hennis AJ, Hambleton IR, Wu SY, et al. Prostate cancer incidence and mortality in Barbados, West Indies. Prostate Cancer. 2011;2011.

http://downloads.hindawi.com/journals/pc/2 011/565230.pdf

19. Pakzad R, Rafiemanesh H, Ghoncheh M, et al. Prostate cancer in Iran: trends in incidence and morphological and epidemiological characteristics. Asian Pac J Cancer Prev. 2016;17(2):839-43.

http://journal.waocp.org/article_31453_1163 1e2d31e3d13be2d5ce5aa02f24d5.pdf

20. Li J, Djenaba JA, Soman A, Rim SH, et al. Recent trends in prostate cancer incidence by age, cancer stage, and grade, the United States, 2001-2007. Prostate cancer. 2012;2012.

https://www.ncbi.nlm.nih.gov/pmc/articles/P MC3515924/pdf/PC2012-691380.pdf

21. Stangelberger A, Waldert $M$, Djavan B. Prostate cancer in elderly men. Reviews in urology. 2008;10(2):111. https://www.ncbi.nlm.nih.gov/pmc/articles/P MC2483315/pdf/RIU010002_0111.pdf

22. Delongchamps NB, Wang CY, Chandan V, Jones RF, Threatte G, Jumbelic M, de la Roza G, Haas GP. Pathological characteristics of prostate cancer in elderly men. The J. Urol.. 2009 Sep 1;182(3):927-30. 
DOI: $10.1016 /$ j.juro.2009.05.018

23. Dasgupta P, Baade PD, Aitken JF, et al. Geographical variations in prostate cancer outcomes: a systematic review of international evidence. FRONT ONCOL. 2019 Apr 8;9:238.

https://www.ncbi.n/m.nih.gov/pmc/articles/P MC6463763/pdf/fonc-09-00238.pdf

24. Hoidy WH, Jaber FA, Al-Askiry MA. Association of CYP1A1 rs1048943 Polymorphism with Prostate Cancer in
Iraqi Men Patients. Asian Pac J Cancer Prev. 2019;20(12):3839.

http://journal.waocp.org/article_88872_706d 8d527ab4cd5dc6ad5ef6c7b8ede3.pdf

25. Khudur KM. Assessment of contributing risk factors for patients with prostate cancer in Capital of Baghdad. Kufa Journal for Nursing sciences. 2012;2(2):38-45.

https://www.iasj.net/iasj?func=fulltext\&ald= 60634 